Henian Cao • Brooke A. Miskie • Robert A. Hegele

\title{
Functional promoter polymorphism in SREBP cleavage-activating protein (SCAP)
}

Received: May 3, 2002 / Accepted: June 11, 2002

\begin{abstract}
We report the identification of a loss-of-function $-11 \mathrm{C}>\mathrm{T}$ promoter mutation in the gene encoding the sterol regulatory element binding protein cleavage-activating protein (SCAP). The $-11 \mathrm{~T}$ allele was associated with a marked reduction in promoter activity in a luciferase-based expression system. We also report additional common single-nucleotide polymorphisms in the SCAP promoter and coding sequence that were identified by using direct sequencing to screen the genomic DNA of subjects with combined hyperlipidemia. These markers might be useful for studies of association with metabolic phenotypes.
\end{abstract}

Key words Metabolism $\cdot$ Cholesterol $\cdot$ Diabetes $\cdot$ Genomic DNA $\cdot$ Sequencing $\cdot$ Complex traits

\section{Introduction}

Cholesterol homeostasis in animal cells is achieved by regulated cleavage of sterol regulatory element binding proteins (SREBPs), which are membrane-bound transcription factors. Proteolytic release of the active domains of SREBPs from membranes requires a sterol-sensing protein called SREBP cleavage-activating protein (SCAP, MIM 601510), which forms a complex with SREBPs. SCAP, a central regulator of lipid synthesis and metabolism, is a membrane protein with multiple membrane-spanning segments, of which some show a highly significant resemblance to the membrane-spanning segments of 3-hydroxy-3-methylglutaryl coenzyme A reductase (MIM 142910) (Hua et al. 1996). Thus, the role of SCAP is to escort the SREBPs from one cellular compartment to another in a sterol-regulated fashion (Osborne 2001). In sterol-depleted cells, SCAP es-

H. Cao $\cdot$ B.A. Miskie $\cdot$ R.A. Hegele $(\square)$

Blackburn Cardiovascular Genetics Laboratory, Robarts Research Institute 406-100 Perth Drive, London, ON, N6A 5K8, Canada Tel. +1-519-663-3461; Fax +1-519-663-3037

e-mail: hegele@robarts.ca corts SREBPs from the endoplasmic reticulum to the Golgi, where SREBPs are cleaved by site-1 protease (DeBoseBoyd et al. 1999). An absence or deficiency of SCAP may reduce the cleavage of SREBPs, thus affecting cellular lipid metabolism and possibly also plasma lipoprotein metabolism. Although common nonsynonymous amino acid polymorphism in SCAP has been identified (Iwaki et al. 1999), there is so far no reported human SCAP mutation that affects its in vitro function or expression. We report the identification of a rare single-nucleotide polymorphism (SNP) in the $S C A P$ promoter in two subjects with combined hyperlipidemia. The expression of a luciferase reporter by a promoter containing this SNP is reduced by twenty-fold compared with the wild-type $S C A P$ promoter. We also report several additional common SNPs in the SCAP promoter and coding sequence.

\section{Methods}

Study subjects

We studied 64 unrelated subjects with a clinical diagnosis of combined hyperlipidemia $(\mathrm{CH})$, defined as plasma triglyceride and low-density lipoprotein (LDL) cholesterol concentration in excess of the 75th percentile for age and sex. Baseline clinical and biochemical attributes of study subjects are shown in Table 1. All subjects were of European descent. We also studied 130 clinically normal unrelated subjects of European descent, 30 unrelated subjects of Chinese descent, and 30 unrelated subjects of African descent. The University of Western Ontario Ethics Review Panel approved the study.

Screening candidate genes by DNA sequencing

Custom primers were designed using GenBank accession numbers 13648747 and XM_033295 and published sequences (Nakajima et al. 1999). Because only exons 9-22 of $S C A P$ encode the primary amino acid sequence, we 
designed primers to amplify only the promoter and these 14 exons. Primers were designed to include at least 50 nucleotides within each intron at each intron-exon boundary, and more than $1 \mathrm{~kb}$ of the $S C A P$ promoter. Primer sequences are shown in Table 2. Amplification conditions for all reactions were $94^{\circ} \mathrm{C}$ for $5 \mathrm{~min}$, followed by 30 cycles of $30 \mathrm{~s}$ each at $94^{\circ} \mathrm{C}, 60^{\circ} \mathrm{C}$, and $72^{\circ} \mathrm{C}$, and ending with a single 10 -min extension step at $72^{\circ} \mathrm{C}$. Purified amplification fragments were sequenced on a Prism 377 Automated DNA Sequencer (Applied Biosystems, Mississauga, Canada), and electropheretograms were interpreted using Sequence Navigator software (Applied Biosystems).

\section{SNP genotyping}

The SCAP promoter SNPs were genotyped from electropheretogram tracings of direct sequencing experiments in subjects of European and Chinese descent only. The $S C A P 1644 \mathrm{G}>\mathrm{A}$ (V>I407) SNP was detected using MslI digestion, as described (Nakajima et al. 1999). One

Table 1. Baseline attributes of combined hyperlipidemia study subjects

\begin{tabular}{lll}
\hline & Males & Females \\
\hline Number & 33 & 31 \\
Age (years) & $46.1 \pm 9.6$ & $53.3 \pm 12.4$ \\
Body mass index $\left(\mathrm{kg} / \mathrm{m}^{2}\right)$ & $29.1 \pm 4.5$ & $34.2 \pm 5.7$ \\
Cholesterol (mmol/l) & & \\
$\quad$ Total & $6.59 \pm 1.43$ & $7.46 \pm 2.52$ \\
$\quad$ Low-density lipoprotein (LDL) & $3.74 \pm 1.00$ & $4.12 \pm 1.93$ \\
$\quad$ High-density lipoprotein (HDL) & $1.04 \pm 0.23$ & $1.14 \pm 0.36$ \\
Triglycerides (mmol/l) & $5.68 \pm 5.46$ & $6.24 \pm 5.85$ \\
\hline
\end{tabular}

Values given as mean $\pm \mathrm{SD}$ additional synonymous SNP was found only in subjects of African descent, namely, exon 11 659A $>$ G. This was detected using primers shown in Table 2 and the amplification program described earlier, followed by digestion of the 582bp product with endonuclease BsmFI. The $659 \mathrm{G}$ allele yielded one fragment with size $582 \mathrm{bp}$, and the 659A allele yielded two fragments with sizes 344 and 238 bp after BsmFI digestion. The polymorphic fragments were resolved on $2 \%$ agarose gels.

\section{Statistical analysis}

SAS version 6.12 (SAS Institute, Cary, NC, USA) was used for statistical analyses. Allele frequencies were determined from gel electrophoresis images or from electropheretogram tracings of genomic DNA sequence. Chi-square analysis tested the deviation of genotype frequencies from Hardy-Weinberg predictions (nominal $P<0.05$ ).

\section{Construction of human SCAP/Luc reporters}

Site-directed mutagenesis of site $-11 \mathrm{C} / \mathrm{T}$ in the SCAP promoter sequence was generated by the two-primer pair method. The mutagenesis primer pair was as follows: FACG CCG CGC TCC GCC CCT GCT GTC GCC CCC GT and R-ACG GGG GCG ACA GCA GGG GCG GAG CGC GGC GT, in which underlines represent mutated nucleotides. A genomic DNA fragment containing a $1.1-\mathrm{kb}$ $S C A P$ promoter sequence was obtained by amplification using primers F-GAA GAT CTC TTA CCT CTG ACA CAA GAC CTG G and R-GAA GAT CTA ACT CCC AGC TCC ACG CGG CTG, and the preceding amplification program. BglII endonuclease restriction sites were

Table 2. Amplification primers for $S C A P$

\begin{tabular}{|c|c|c|}
\hline Region & Primers & Fragment size (bp) \\
\hline Promoter & $\begin{array}{l}\text { F-GGC TTA CCT CTG ACA CAA GAC CTG G } \\
\text { R-AAC TCC CAG CTC CAC GCG GCT G }\end{array}$ & 1161 \\
\hline Exon 9 & $\begin{array}{l}\text { F-GCC CAT GAG GTT GTG TGA GT } \\
\text { R-AGG ATG CCT GTG CTG AAG AG }\end{array}$ & 273 \\
\hline Exons 10 and 11 & $\begin{array}{l}\text { F-ATC CCA TGT GCT CTG ATT C } \\
\text { R-TCT AAG GCC AAG TGC AGC }\end{array}$ & 582 \\
\hline Exon 12 & $\begin{array}{l}\text { F-CCC ATT CCT CCC ACT GAG TA } \\
\text { R-TAA TTC AAA CCT GTG GGC CT }\end{array}$ & 506 \\
\hline Exon 13 & $\begin{array}{l}\text { F-ACA GCA GGA GGA AGC CCT } \\
\text { R-CAC CCA GCA GCC TTA CTT GT }\end{array}$ & 263 \\
\hline Exon 14 & $\begin{array}{l}\text { F-AGG CAA GAG TAG GGG AGA GG } \\
\text { R-AGA AGC CCG GTG TTG GTA T }\end{array}$ & 348 \\
\hline Exon 15 & $\begin{array}{l}\text { F-CTG GCC CAT ACC AAC ACC } \\
\text { R-GGG GCA CAA AGG AGG AAA G }\end{array}$ & 180 \\
\hline Exon 16 & $\begin{array}{l}\text { F-CTC TCA CTC CGC CCT CCT } \\
\text { R-AGA AAG GCC CAC AAT CCC }\end{array}$ & 612 \\
\hline Exon 17 & $\begin{array}{l}\text { F-CTA AAG GTG GGC AGA GCG } \\
\text { R-TAT GGC CTA GCC AAC AAA GG }\end{array}$ & 225 \\
\hline Exons 18 and 19 & $\begin{array}{l}\text { F-CAG GGC TGG GGC TCT AAG } \\
\text { R-GGG AAA TGC CCT CTG TTC TT }\end{array}$ & 520 \\
\hline Exons 20 and 21 & $\begin{array}{l}\text { F-CTT GGA AAA TCC CAG AGA CCA } \\
\text { R-AGC TCA GTC CTG AGT CCT TCC }\end{array}$ & 580 \\
\hline Exon 22 & $\begin{array}{l}\text { F-GGG ATC ATA GGA TTC TTG GGA } \\
\text { R-AGA TAC TCG GCT CTT TCC CC }\end{array}$ & 405 \\
\hline
\end{tabular}


introduced into both primers. The promoter fragment could thus be subcloned into the $B g l \mathrm{II}$ site of the luciferase reporter, PGL3 basic vector (Promega, Madison, WI, USA). The fidelity of polymerase chain reaction replication and the introduction of the $-11 \mathrm{~T}$ mutation were subsequently confirmed by DNA sequence analysis.

\section{Cell culture}

The mouse cell line NIH-3T3 was obtained from the American Type Culture Collection (ATCC, Manassas, VA, USA). The cells were grown in Dulbecco's Modified Eagle's Medium (Invitrogen, Carlsbad, CA, USA) supplemented with $100 \mathrm{U} / \mathrm{ml}$ penicillin, $100 \mu \mathrm{g} / \mathrm{ml}$ streptomycin, and $10 \% \quad(\mathrm{v} / \mathrm{v})$ heated-inactivated fetal calf serum (Invitrogen).

\section{Transient transfection assay}

The NIH-3T3 cell cultures that were grown in six-well culture plates were transfected with plasmid by a standard calcium phosphate precipitation method (www.stanford.edu/group/nolan/index.html). Cells were seeded on six-well plates to achieve $60 \%-70 \%$ confluence and transfected with SCAP promoter reporter constructs containing either mutant or the control promoter sequence in either correct or reverse orientation. For each transfection, we prepared the DNA $(8 \mu \mathrm{g} / 60 \mathrm{~mm})$ in a specified amount of $2 \times$ HEPES buffered saline and $2 \mathrm{M} \mathrm{CaCl}_{2}$ solution, and added the solution dropwise to the cells. For each transfection with the SCAP-containing vector, $2 \mu \mathrm{g}$ pSVbeta-galactosidase vector (ProFection Mammalian Transfection System, Promega) was cotransfected according to the manufacturer's instructions. The transfection solution was removed after $20 \mathrm{~h}$ incubation at $37^{\circ} \mathrm{C}$ and replaced by fresh medium for a further culture. Cells were harvested $48 \mathrm{~h}$ posttransfection, and the reporter activity was determined with the luciferase assay. The beta-galactosidase enzyme assay system was used for normalization (Promega). For beta-galactosidase assays, $150 \mu \mathrm{l}$ cell lysate was mixed with $150 \mu \mathrm{l} 2 \times$ assay buffer and incubated at $37^{\circ} \mathrm{C}$ for $3 \mathrm{~h}$. The reaction was stopped by the addition of $500 \mu \mathrm{l}$ of $1 \mathrm{M}$ sodium carbonate and absorbance at $420 \mathrm{~nm}$ was read spectrophotometrically. A blank was prepared using the lysate made from cells that were not transfected with the beta-galactosidase gene.

\section{Luciferase reporter assay}

Luciferase activity was assayed according to the manufacturer's instructions (Promega) and luminescence was determined using a Lumat LB9507 luminometer (Berthold Systems, Pittsburgh, PA, USA). Luciferase activities were normalized for transfection efficiencies using reporter luciferase units per unit of activity of beta-galactosidase (RLU/B-Gal). Each data point was the average of triplicate assays from two experiments.

\section{Results}

Identification of SCAP polymorphisms

Genomic DNA sequencing experiments in $64 \mathrm{CH}$ and 130 normal control subjects uncovered seven SCAP polymorphisms (Table 3). All observed genotype frequencies did not deviate from Hardy-Weinberg expectations. There were four common promoter SNPs, namely, $-933 \mathrm{G}>\mathrm{A}$, $-440 \mathrm{~T}>\mathrm{A},-439 \mathrm{C}>\mathrm{A}$, and $-177 \mathrm{G}>\mathrm{C}$. These were frequent in both diseased subjects and in controls from three ethnic groups (Table 3 ). The $-933 \mathrm{G},-440 \mathrm{~A}$, and $-439 \mathrm{~A}$ allele were in almost perfect linkage disequilibrium and formed a common haplotype in all subgroups examined (coefficient of disequilibrium $>0.95$ for each ethnic group). A silent SNP in exon 11, namely, 659A $>\mathrm{G}$, was observed only in subjects of African descent (Table 3). The previously reported non-synonymous exon $151644 \mathrm{G}>\mathrm{A}$ SNP (Iwaki et al. 1999) was found at varying frequency in all ethnic groups. Finally, a rare promoter SNP $-11 \mathrm{C}>\mathrm{T}$ was found only in two subjects with $\mathrm{CH}$. The affected heterozygotes for the $S C A P-11 \mathrm{C}>\mathrm{T}$ SNP were (1) a 54-year-old man with untreated plasma concentrations of total, LDL, and high-density lipoprotein (HDL) cholesterol of 5.17, 3.70 , and $0.79 \mathrm{mmol} / 1$, respectively, and a plasma triglyceride concentration of $2.70 \mathrm{mmol} / 1$; and (2) a 57 -year-old woman with untreated plasma concentrations of total,

Table 3. SNPs and mutations identified in the $S C A P$ gene

\begin{tabular}{|c|c|c|c|c|c|c|}
\hline \multirow[b]{2}{*}{ Region } & \multirow[b]{2}{*}{ Variant Name } & \multirow[b]{2}{*}{ Detection method } & \multicolumn{4}{|c|}{ Allele frequencies } \\
\hline & & & $\mathrm{CH}$ & $\begin{array}{l}\text { Controls } \\
\text { European }\end{array}$ & African & Chinese \\
\hline \multirow[t]{5}{*}{ Promoter } & $-933 \mathrm{G}>\mathrm{A}$ & Direct sequencing & $-933 \mathrm{~A}: 0.50$ & 0.55 & 0.60 & 0.47 \\
\hline & $-440 \mathrm{~T}>\mathrm{A}$ & Direct sequencing & $-440 \mathrm{~A}: 0.50$ & 0.45 & 0.40 & 0.43 \\
\hline & $-439 \mathrm{C}>\mathrm{A}$ & Direct sequencing & $-439 \mathrm{~A}: 0.50$ & 0.45 & 0.40 & 0.43 \\
\hline & $-177 \mathrm{G}>\mathrm{C}$ & Direct sequencing & $-177 \mathrm{C}: 0.00$ & 0.07 & 0.00 & 0.00 \\
\hline & $-11 \mathrm{C}>\mathrm{T}$ & Direct sequencing & $-11 \mathrm{~T}: \quad 0.02$ & 0.00 & 0.00 & 0.00 \\
\hline Exon 11 & $659 \mathrm{~A}>\mathrm{G}$ & BsmFI & 659G: & 0.00 & 0.23 & 0.00 \\
\hline Exon 15 & $1644 \mathrm{G}>\mathrm{A}$ & MslI digestion & 1644A: 0.53 & 0.53 & 0.25 & 0.08 \\
\hline
\end{tabular}

$\mathrm{CH}$, Combined hyperlipidemia 


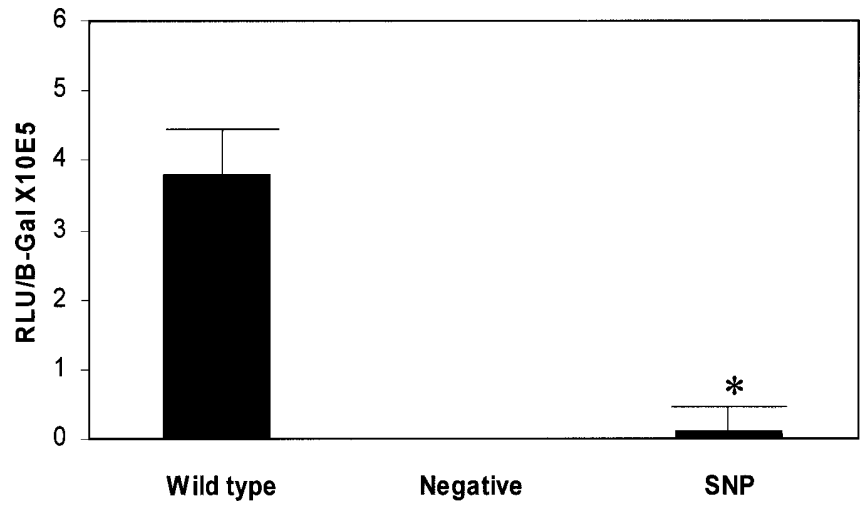

Fig. 1. Results of in vitro expression analysis of luciferase reporter constructs containing wild-type $S C A P$ promoter (WT), a negative control construct made by cloning of WT promoter in the reverse orientation (negative), and a construct containing the $-11 \mathrm{C}>\mathrm{T}$ polymorphism $(S N P)$. Normalized reporter luciferase units $(R L U)$ per unit of betagalactosidase activity $(B-G a l)$ are shown for two sets of triplicate experiments. Means \pm standard deviations are shown. The asterisk refers to a significant difference between mean WT and SNP normalized expression $(P<0.001)$

LDL, and HDL cholesterol of 5.77, 3.56, and $0.99 \mathrm{mmol} / 1$, respectively, and a plasma triglyceride concentration of $7.26 \mathrm{mmol} / \mathrm{L}$. Each subject was apparently a sporadic hyperlipidemic patient with no living relatives available for study. Chi-square analysis showed no significant difference in allele frequency between subjects with $\mathrm{CH}$ and normal Caucasian controls $(P=0.56)$.

\section{$S C A P$ promoter activity assay}

Sequencing showed that the background promoter sequence for each reporter construct contained -933G, $-440 \mathrm{~T},-439 \mathrm{C}$, and $-177 \mathrm{G}$. The difference was the presence of $-11 \mathrm{C}$ for the wild-type construct and $-11 \mathrm{~T}$ for the mutant construct. The negative control construct contained the wild-type sequence, but in the reverse orientation. Mean normalized luciferase activities from triplicate experiments performed on two separate days are shown in Fig. 1. The normalized luciferase activity (RLU) was decreased by more than 20-fold for the mutant compared with the wild type $(P<0.001)$.

\section{Discussion}

We report the identification of a loss-of-function $-11 \mathrm{C}>\mathrm{T}$ promoter mutation for $S C A P$. This mutation was found in two unrelated subjects who were ascertained based on a biochemical diagnosis of $\mathrm{CH}$, but was absent from normolipidemic subjects across three ethnic groups. The $-11 \mathrm{~T}$ allele was associated with a marked reduction in promoter activity in a luciferase-based expression system.

It is not clear whether heterozygosity for a dysfunctional promoter mutation in $S C A P$, even one associated with as severe loss of function in an in vitro expression assay as $-11 \mathrm{C}>\mathrm{T}$, would be associated with any consequence at the clinical level. Liver-specific targeted deletion of $S C A P$ in mice resulted in low serum concentrations of cholesterol and triglycerides (Matsuda et al. 2001), which was opposite to the $\mathrm{CH}$ phenotype observed in heterozygotes for $-11 \mathrm{C}>\mathrm{T}$. Because SREBPs are key activators of lipogenesis, the liver-specific-SCAP-less mice cannot appropriately escort SREBP promoters to cellular compartments containing the proteases that produce active SREBP cleavage products, which results in diminished lipogenesis under both fasting and fed conditions (Matsuda et al. 2001; Osborne 2001). However, human heterozygotes for $S C A P-11 C>\mathrm{T}$ differ from liver-specific-SCAP-less mice, because there is only a partial reduction in the capacity to generate normal SCAP, and this occurs in both hepatic and extrahepatic tissues. This distinction, taken together with interspecies differences and the overall complexity of cholesterol metabolism and fatty acid biosynthesis, could explain the apparently counterintuitive human phenotype.

Another potential confounding issue is that of tissue specificity. Our assay of promoter function was determined in a murine adipocyte cell line. Although NIH-3T3 cells were previously shown to be useful for analyzing SREBP activation (Inoue et al. 2001), it remains possible that there are differences between cell lines. In addition, there might also have been unmeasured genetic and/or environmental factors that could have affected expression of the phenotype in the human $S C A P-11 \mathrm{C}>\mathrm{T}$ heterozygotes in whom the mutation was first identified. Alternatively, this rare loss-of-function $S C A P$ promoter mutation may have played no role in the abnormal lipoprotein phenotype in the two affected subjects, and was simply an incidental finding. Studies of much larger experimental samples will be required to establish whether there is a statistical association between the rare loss-of-function mutation in SCAP and a dyslipidemic phenotype.

We also found additional promoter SNPs in SCAP, namely, $\quad-933 \mathrm{G}>\mathrm{A}, \quad-440 \mathrm{~T}>\mathrm{A}, \quad-439 \mathrm{C}>\mathrm{A}, \quad$ and $-177 \mathrm{G}>\mathrm{C}$, which were common in control subjects from three ethnic groups. We also identified a silent SNP in exon 11 , namely, 659A $>\mathrm{G}$, which was observed only in subjects of African descent. In addition, we found that the frequency of a previously reported common nonsynonymous $S C A P$ SNP, namely, 1644G $>$ A (Iwaki et al. 1999), varied in frequency across ethnic groups. The identification of additional SCAP SNPs provides tools for studies of association with metabolic phenotypes.

Acknowledgments Pearl Campbell provided outstanding technical assistance. Dr. Hegele holds a Canada Research Chair (Tier I) in Human Genetics and a Career Investigator award from the Heart and Stroke Foundation of Ontario. This work was supported by grants from Canadian Institutes for Health Research (MT13430), the Canadian Diabetes Association (\#992, in honor of Hazel E. Kerr), the Canadian Genetic Diseases Network, and the Blackburn Group. 


\section{References}

DeBose-Boyd RA, Brown MS, Li W-P, Nohturfft A, Goldstein JL, Espenshade PJ (1999) Transport-dependent proteolysis of SREBP: relocation of Site-1 protease from Golgi to ER obviates the need for SREBP transport to Golgi. Cell 99:703-712

Hua X, Nohturfft A, Goldstein JL, Brown MS (1996) Sterol resistance in $\mathrm{CHO}$ cells traced to point mutation in SREBP cleavage-activating protein. Cell 87:415-426

Inoue J, Kumagai H, Terada T, Maeda M, Shimizu M, Sato R (2001) Proteolytic activation of SREBPs during adipocyte differentiation. Biochem Biophys Res Commun 283:1157-1161

Iwaki K, Nakajima T, Ota N, Emi M (1999) A common Ile796Val polymorphism of the human SREBP cleavage-activating protein (SCAP) gene. J Hum Genet 44:421-422
Matsuda M, Korn BS, Hammer RE, Moon YA, Komuro R, Horton JD, Goldstein JL, Brown MS, Shimomura I (2001) SREBP cleavageactivating protein (SCAP) is required for increased lipid synthesis in liver induced by cholesterol deprivation and insulin elevation. Genes Dev 15:1206-1216

Nakajima T, Hamakubo T, Kodama T, Inazawa J, Emi M (1999) Genomic structure and chromosomal mapping of the human sterol regulatory element binding protein (SREBP) cleavage-activating protein (SCAP) gene. J Hum Genet 44:402-407

Osborne TF (2001) CREating a SCAP-less liver keeps SREBPs pinned in the ER membrane and prevents increased lipid synthesis in response to low cholesterol and high insulin. Genes Dev 15:18731878 